\title{
APT/LEDA TUNNEL FLOOR RANDOM VIBRATION MEASUREMENTS *
}

\author{
Stephen Ellis ${ }^{\dagger}$, Los Alamos National Laboratory \\ Los Alamos, New Mexico 87545, USA
}

\begin{abstract}
Mechanical vibration spectra have been measured periodically on the tunnel floor below the APT/LEDA RFQ since installation in May of 1998. Facility vibration levels are of concern because if excessive, they will degrade the performance of vibration sensitive components and thus overall accelerator performance. The measured spectra accurately quantify the accelerator's mechanical vibration environment, permitting reasonably accurate finite element calculations of the hardware dynamic response. Identification of the various vibration sources, as well as detection of anomalous vibration sources, is also readily performed. The vibratory environment is largely due to nearby operating mechanical equipment such as coolant pumps, vacuum pumps, compressors and blowers. Input from external natural sources such as wind and flowing water as well as man-made sources such as traffic are also present.
\end{abstract}

\section{VIBRATION MEASUREMENT}

Vibration measurements were taken below the RFQ on the tunnel floor adjacent to the RFQ support frame aft kinematic mount. Bruel and Kjaer seismic accelerometers, model 8318 , of approximately $3-\mathrm{V} / \mathrm{g}$ sensitivity were utilized. The accelerometers were fastened with wax directly to the floor for vertical (y-axis) measurements and to the lateral (x-axis) and longitudinal (z-axis, parallel to the beam line) faces of the mount base plate for measurement along these respective directions.

Vibration measurements were conducted while ancillary equipment was installed and placed in service as the RFQ installation was being completed. This eased identification of the specific vibration contributions, if any, from specific pieces of equipment. Measured spectra since equipment installation was completed and RF conditioning of the RFQ began have been relatively consistent. Surveys of existing operational equipment in and near the LEDA facility were also conducted.

A Data Physics Corporation SignalCalc Ace twochannel dynamic signal analyzer and an IBM laptop PC were utilized for data acquisition and post processing. Measurements were made with all measurement equipment operating under battery power to minimize interference and noise transmitted through the facility $\mathrm{AC}$ electric service.

Power Spectral Density (PSD) plots for the three coordinate axes are plotted in Figure 1. These particular measurements were taken March 30, 2000. The spectra show sharp well-defined spectral lines, corresponding to strong vibration sources operating steadily at specific frequencies. Lower level broadband signal content is also present, corresponding to single or multiple vibration sources of a more random nature.

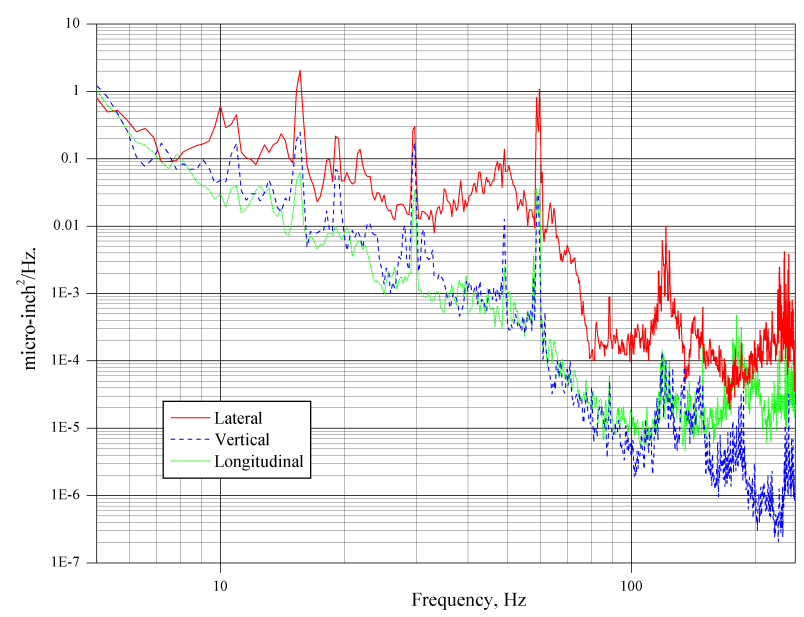

Figure 1: Typical Vibration PSD Displacement Traces

The vertical and axial spectra are similar with respect to magnitude and specific frequency content. The lateral spectrum, in comparison, is generally greater in magnitude. The waveguide basement through which all $\mathrm{RF}$ waveguide is routed is situated parallel to, and below the RFQ. The section of tunnel floor structure to which the RFQ is mounted is actually the top surface of the waveguide basement North wall. The measured lateral vibration levels are believed to be greater due to lateral compliance of the wall with respect to its much stiffer vertical and longitudinal axes. Lateral vibration spectra measured on the tunnel floor away from the waveguide basement are similar, as expected, to the longitudinal vibration spectra.

Conservative enveloping of the three PSD traces was completed to provide simplified PSD curves for use when calculating response of equipment and structures in the facility. The envelopes are plotted in Figure 2, and their respective breakpoints are listed in Table 1. An envelope corresponding to measurements made during the GTA program in 1991 at the same location is also included for comparison. The RMS displacement values corresponding to each envelope were calculated and are listed on the plot as well.

These spectra were utilized to create an estimated baseline vibration environment for the SNS linac, a new machine, presently under final stages of engineering and design [1]. The estimated vibration environment will be used to support engineering calculations concerning the predicted dynamic response of motion sensitive equipment.

\footnotetext{
* Work supported by the US DOE, NNSA and the Office of

Nuclear Energy, Science and Technology.

†ellis@lanl.gov
} 


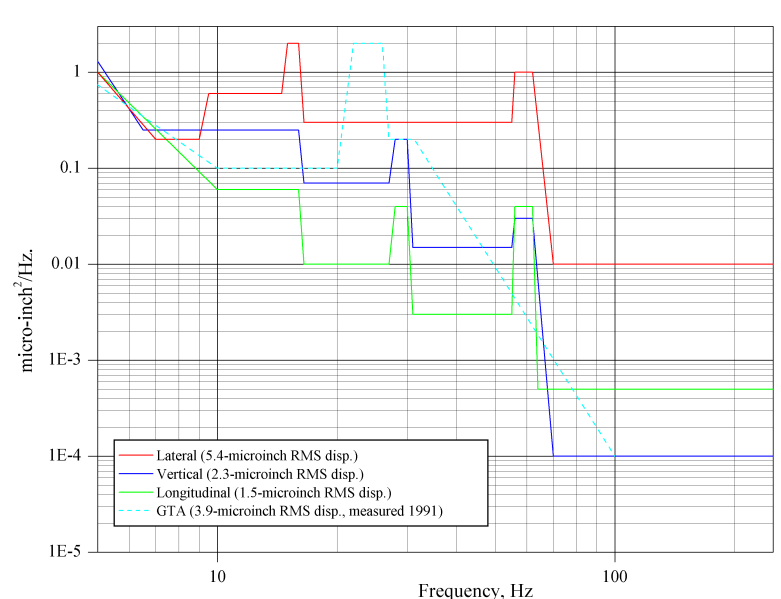

Figure 2: Floor Vibration PSD Displacement Envelopes

Table 1: Vibration Environment Spectrum Envelope Break Points

\begin{tabular}{|c|c|c|c|c|c|}
\hline \multicolumn{2}{|c|}{ X-axis } & \multicolumn{2}{c|}{ Y-axis } & \multicolumn{2}{c|}{ Z-axis } \\
\hline $\begin{array}{c}\text { Frequency } \\
(\mathrm{Hz})\end{array}$ & $\begin{array}{c}\text { Input } \\
\left(\mu \mathrm{in}^{2} / \mathrm{Hz}\right)\end{array}$ & $\begin{array}{c}\text { Frequency } \\
(\mathrm{Hz})\end{array}$ & $\begin{array}{c}\text { Input } \\
\left(\mu \mathrm{in}^{2} / \mathrm{Hz}\right)\end{array}$ & $\begin{array}{c}\text { Frequency } \\
(\mathrm{Hz})\end{array}$ & $\begin{array}{c}\text { Input } \\
\left(\mu \mathrm{in}^{2} / \mathrm{Hz}\right)\end{array}$ \\
\hline 5.0 & 1.00 & 5.0 & 1.30 & 5.0 & 1.00 \\
\hline 7.0 & 0.20 & 6.5 & 0.25 & 10.0 & 0.06 \\
\hline 9.0 & 0.20 & 16.0 & 0.25 & 16.0 & 0.06 \\
\hline 9.5 & 0.60 & 16.5 & 0.07 & 16.5 & 0.01 \\
\hline 14.5 & 0.60 & 27.0 & 0.07 & 27.0 & 0.01 \\
\hline 15.0 & 2.00 & 28.0 & 0.20 & 28.0 & 0.04 \\
\hline 16.0 & 2.00 & 30.0 & 0.20 & 30.0 & 0.04 \\
\hline 16.5 & 0.30 & 31.0 & $1.50 \mathrm{E}-2$ & 31.0 & $3.00 \mathrm{E}-3$ \\
\hline 55.0 & 0.30 & 55.0 & $1.50 \mathrm{E}-2$ & 55.0 & $3.00 \mathrm{E}-3$ \\
\hline 56.0 & 1.00 & 56.0 & 0.03 & 56.0 & 0.04 \\
\hline 62.0 & 1.00 & 62.0 & 0.03 & 62.0 & 0.04 \\
\hline 70.0 & 0.01 & 70.0 & $1.00 \mathrm{E}-4$ & 64.0 & $5.00 \mathrm{E}-4$ \\
\hline 250.0 & 0.01 & 250.0 & $1.00 \mathrm{E}-4$ & 250.0 & $5.00 \mathrm{E}-4$ \\
\hline
\end{tabular}

\section{VIBRATION SOURCES}

Described below are general vibration sources that are always present at some level at all locations. Also described are some specific sources associated with the LEDA facility and consequently related to accelerator facilities in general.

\subsection{Natural Sources}

Natural mechanisms that create vibration at levels that may be of concern include flowing surface and subsurface water, wind acting on buildings and nearby tree stands, ocean wave action on near as well as distant beaches, and low-level seismic activity or microseisms. These sources generally contribute to the vibration environment at the lower portion of the spectrum, usually in a very random manner. The measured spectra contain broadband non-distinct signal content or noise that was above the measured equipment noise floor that is presumed in part due to these sources.

\subsection{Cultural Sources}

Cultural or man-made vibration sources external to the facility that may be significant in magnitude consist primarily of vehicular traffic, nearby construction activity and nearby industrial activity. The APT/LEDA facility is relatively quiet with respect to these inputs. The facility is ideally located on a remote mesa far from any significant population and its associated vibration transmissions. Nearby roadways are relatively lightly traveled, well paved and there are no nearby bus routes or railways. Input due to heavy truck traffic was detected and may be significant but occurs infrequently, for short time durations.

Construction activity and heavy equipment operation does occasionally occur near the facility. As expected, there is considerable impact on the linac vibration environment during this type of event but this is an infrequent occurrence and thus is not considered part of the normal linac vibration environment.

There are other experimental facilities on the mesa with ongoing mechanized activities that disperse low-level vibration. A portion of the vibration measured in the LEDA facility is presumed due to contributions from these sources as well as the natural sources described above.

\subsection{Facility Specific Sources}

A large portion of the ambient vibration environment is due to equipment operating within the facility. A large portion of this equipment is located within close proximity to the linac and thus has strong influence on its vibration environment. The primary sources are discussed below.

\subsubsection{Tunnel Ventilation System}

The LEDA tunnel ventilation system incorporates a large blower, which draws air from the tunnel and vents through a large stack on the North side of building. The blower is powered with a 100-Hp AC electric motor, which is controlled with a variable speed motor drive. The operating speed is set to maintain a specified airflow in the tunnel. This blower is located in an equipment room above the tunnel. The spectral peaks at $15.6-\mathrm{Hz}$ corresponds to this input.

The blower and motor are mounted on a vibration isolation structure. Vibration measurements were made on the motor body and also on the floor where the vibration isolation mount fastens. Significant vibration attenuation through the isolation structure was evident.

\subsubsection{AC Induction Motor Powered Equipment}

Two-pole AC induction motors are by far the most common class of electric motors utilized throughout the 
facility. Equipment powered by these motors includes the numerous vacuum roughing pumps, HVAC pumps and blowers and linac cooling system pumps. The larger RFQ cooling system pump motors, ranging from 60 to $150-\mathrm{Hp}$, are also of this design. These motors typically operate at speeds from 1715-RPM to 1760-RPM primarily inducing vibration just below $30-\mathrm{Hz}$. The peaks near $29-\mathrm{Hz}$ on the spectra correspond equipment powered with these motors. Harmonics of this specific input are also sometimes present

Four-pole induction motors are also quite common. Typical speeds for these motors are 3450-RPM to 3560RPM. The RF windows utilize 10-Hp blowers for cooling which operate at 3450-RPM. All of the smaller RFQ cooling system pump motors in the 30 to 60 -Hp power range are this type. The beam stop cooling system incorporates a 30-Hp 3525-RPM pump motor. The peak near $57.2-\mathrm{Hz}$ corresponds equipment powered with these motors. Harmonics for this input are also sometimes present.

Measurements have also been made when all facility electrical power was disconnected while carrying out facility electrical service upgrades. The spectral peaks corresponding to two-pole and four-pole AC motors were still present but of lower amplitude. These particular signals are evidently generated by operating motors in nearby buildings and propagate through the soil to the LEDA facility.
The peaks just below $60-\mathrm{Hz}$ correspond to the RFQ cooling system variable flow coolant pumps. These pumps are mounted along the South tunnel wall parallel to the RFQ. Each pump is directly coupled to a $30-\mathrm{Hp}$ electric motor. Each motor is powered with a variable frequency drive motor controller that permits variability of motor speed and thus coolant flow rate. Nominal $100 \%$ pump speed corresponds to 3560-RPM. Typical pump operation speeds during RFQ operation will be $95 \%$ to $105 \%$. Adjustment of the speed of these pumps and speed differences between individual pumps was always perceptible with the vibration measurement apparatus.

\subsubsection{Flow Induced Vibration}

The broadband hash or noise present on the spectra above $100-\mathrm{Hz}$ corresponds to operation of the RFQ cooling system and is coolant flow-induced vibration. Similar spectral behavior has been observed with similar systems. The measured input is of relatively low magnitude that corresponds to the systems relatively low velocity flow.

\section{REFERENCES}

[1] S. Ellis, "Estimated Vibratory Environment, SNS Accelerator Tunnel”, SNS00-TCN-0248, LANL, (22 September 2000) 